EPJ Web of Conferences 29, 00004 (2012)

DOI: $10.1051 /$ epjconf/20122900004

(C) Owned by the authors, published by EDP Sciences, 2012

\title{
Effect of Fe doping on properties of $\mathrm{Pr}_{0.67} \mathrm{Ba}_{0.33} \mathrm{Mn}_{1-\mathrm{x}} \mathrm{Fe}_{\mathrm{x}} \mathrm{O}_{3}$ perovskites
}

\author{
M. Baazaoui ${ }^{\mathrm{a} 1,2}$, M. Boudard ${ }^{2}$, S. Zemni $1^{\text {a }}$, V. Nassif ${ }^{3,4}$, F. Gay ${ }^{3}$, M. Oumezzine $^{1}$ \\ ${ }^{1}$ Laboratoire de Physico-Chimie des Matériaux, Faculté des Sciences de Monastir, Département de \\ Physique, 5019, Université de Monastir, Monastir, Tunisie. \\ ${ }^{2}$ Laboratoire des Matériaux et du Génie Physique (CNRS UMR 5628), Minatec Bâtiment INPG, \\ parvis Louis Néel, BP 257, 38016 Grenoble Cedex 1, France. \\ ${ }^{3}$ Institut Néel (CNRS and UJF), BP 166, 38042 Grenoble Cedex 9, France \\ ${ }^{4}$ Institut Laue Langevin, BP 156, 38042 Grenoble Cedex 9, France
}

\begin{abstract}
Changes in the physical properties of ceramic $\operatorname{Pr}_{0.67} \mathrm{Ba}_{0.33} \mathrm{Mn}_{1-\mathrm{x}} \mathrm{Fe}_{\mathrm{x}} \mathrm{O}_{3}(0 \leq \mathrm{x} \leq$ 0.15 ) are interpreted as resulting from the suppression of the ferromagnetic double exchange interaction with almost no lattice effect due to similar ionic radii value of $\mathrm{Fe}^{3+}$ and $\mathrm{Mn}^{3+}$ Magnetization and transport measurements show at low temperature ferromagnetic and metallic behavior for $\mathrm{x}=0$ and 0.05 samples, whereas $\mathrm{x}=0.10$ and $\mathrm{x}=$ 0.15 compounds show spin glass like and semiconducting behavior. At high temperature semiconductor and paramagnetic behavior are observed for all the samples.

Keywords: Magnetic materials; X-ray diffraction; Physical properties.
\end{abstract}

PACS: 61,75

\section{Introduction}

Manganites perovskite oxides were widely studied in the last two decades after the discovery of colossal magnetoresistance $(\mathrm{CMR})$ [1]. Below the Curie temperature $\left(\mathrm{T}_{\mathrm{C}}\right)$ ferromagnetic $(\mathrm{FM})$ and metallic behavior (obtained by creation of mixed $\mathrm{Mn}^{3+} / \mathrm{Mn}^{4+}$ valence when doping) were explained within the double exchange (DE) mechanism [2]. Polaronic type model [3] or segregation phase models $[4,5]$ were then introduced to fully explain the transport behavior above $\mathrm{T}_{\mathrm{C}}$ and the CMR properties.

Among divalent doped systems, those with $\mathrm{Ba}$ content remains less investigated despite the initial discovery of the CMR effect in $\mathrm{La}_{0.67} \mathrm{Ba}_{0.33} \mathrm{MnO}_{3}$ thin films [6] (see [4] and [7] and references therein). Recently we have investigated $\mathrm{La}_{0.67} \mathrm{Ba}_{0.33} \mathrm{Mn}_{1-\mathrm{x}} \mathrm{TM}_{\mathrm{x}} \mathrm{O}_{3}$ systems with $\mathrm{TM}=\mathrm{Ti}^{4+}$ [7] and $\mathrm{Fe}^{3+}$ [8]. The effect of trivalent magnetic $\left(\mathrm{Fe}^{3+}\right)$ or tetravalent non- magnetic $\left(\mathrm{Ti}^{4+}\right)$ substitution for $\mathrm{Mn}$ on magnetic and electrical properties [7-9] appears quite similar in both systems and eliminates the ferromagnetic/metallic (FM/M) and paramagnetic/ insulator (PM/I) transitions in these systems. More recently we have shown that the $\mathrm{Pr}_{0.67} \mathrm{Ba}_{0.33} \mathrm{Mn}_{1-\mathrm{x}} \mathrm{Fe}_{\mathrm{x}} \mathrm{O}_{3}$ iron doped systems presents very interesting magnetocaloric properties [10]. In this paper we report in more details its structural, magnetic and electrical properties that appear quite similar to previous Ba-doped studied system.

\footnotetext{
a e-mail : medbaazaoui@yahoo.fr
} 


\section{Experimental}

Samples with nominal compositions $\mathrm{Pr}_{0.67} \mathrm{Ba}_{0.33} \mathrm{Mn}_{1-\mathrm{x}} \mathrm{Fe}_{\mathrm{x}} \mathrm{O}_{3}(0 \leq \mathrm{x} \leq 0.15)$ were prepared by solid state reaction using $\mathrm{Pr}_{6} \mathrm{O}_{11}, \mathrm{BaCO}_{3}, \mathrm{Mn}_{2} \mathrm{O}_{3}$ and $\mathrm{Fe}_{2} \mathrm{O}_{3}$ with similar thermal treatment as the one used in $[8,9]$. The samples are finally annealed at $1453 \mathrm{~K}$ for $24 \mathrm{~h}$ in air. Microstructure and composition of the samples were studied by scanning electron microscopy (SEM) using a Philips XL30 microscope with an energy dispersive X-ray (EDX) spectrometer working at $20 \mathrm{kV}$. Powder X-ray diffraction (XRD) were collected using Co-K $\alpha$ radiation in the $2 \theta$ range $20^{\circ}-100^{\circ}$ with a step size of $0.017^{\circ}$ and a counting time of $18 \mathrm{~s}$ per step at room temperature (RT). Powder neutron diffraction (PND) experiment was carried out at Institut Laue Langevin on D1B diffractometer using $2.52 \AA$ wavelength and a multidetector covering a $2 \theta$ angular range from $37^{\circ}-117^{\circ}$ at $\mathrm{RT}$. Rietveld structure refinement was carried out using the FULLPROF software [11]. Magnetization $(M)$ was measured using a linear extracting magnetometer. Temperature dependence $(M(T))$ was measured either with zero field cooled (ZFC)) and field cooled (FC) samples. Applied magnetic field $(M(H))$ dependence was measured at $10 \mathrm{~K}$ up to $H=100 \mathrm{kOe}$. Transport properties were measured by four probe methods.

\section{Results and discussion}

\subsection{Microstructure and structural analyses}
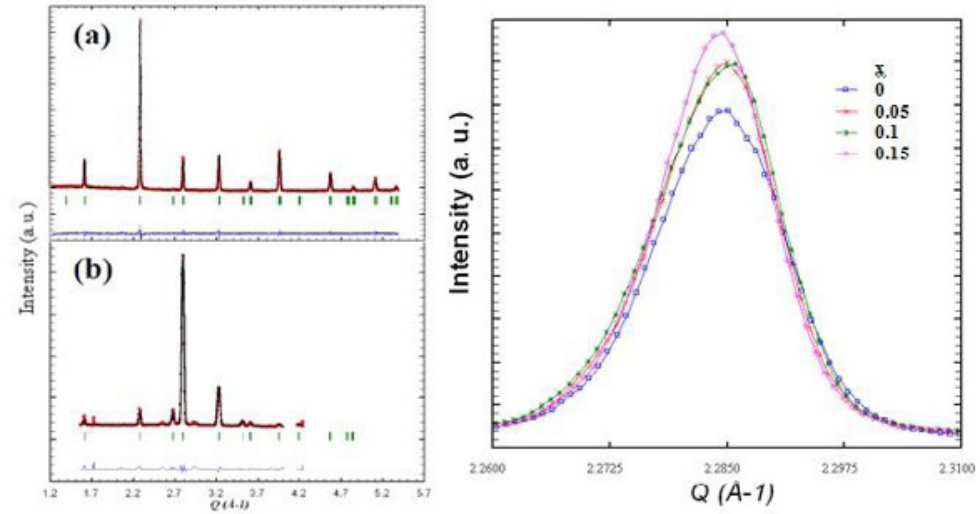

Fig 1. (a) XRD and ((b) PND Rietveld refinement results for sample with $x=0.05$ at RT. The difference between measured (red) and calculated data (black) is plotted below (blue). Vertical green lines correspond to

Bragg positions. (c) XRD shows a negligible shift of the most intense peak when Fe amount increases.

SEM, XRD and PND observations show for all the samples a unique phase with 1 to $2 \mu \mathrm{m}$ average grain size. EDX observations on $100 \mu \mathrm{m} \times 100 \mu \mathrm{m}$ regions show that $\mathrm{Pr}, \mathrm{Ba}, \mathrm{Mn}$ and $\mathrm{Fe}$ compositions are close to the nominal ones. Only slight structural modifications are observed by XRD and PND on Fe doping (see peak position evolution on Fig. 1 (c)). Indexing of the diffractograms and Rietveld structure refinements was performed using orthorhombic Imma symmetry [12, 13].

The $(\mathrm{Pr}, \mathrm{Ba})$ atoms are at $4 \mathrm{e}(0,1 / 4, \mathrm{z})$ position, $(\mathrm{Mn}, \mathrm{Fe})$ at $4 \mathrm{~b}(0,0,1 / 2), \mathrm{O}(1)$ at $4 \mathrm{e}(0,1 / 4, \mathrm{z})$ and $\mathrm{O}(2)$ at $8 \mathrm{~g}(1 / 4,-\mathrm{y}, 3 / 4)$. Refinement results are listed in table 1 , and show that the average structure as a function of Fe substitution appears almost constant as expected from similar ionic radii of $\mathrm{Fe}^{3+}$ and $\mathrm{Mn}^{3+}$ ions $(0.645 \AA[14])$. 
Table 1. Structural parameters for XRD and PND Rietveld refinement for $\operatorname{Pr}_{0.67} \mathrm{Ba}_{0.33} \mathrm{Mn}_{1-\mathrm{x}} \mathrm{Fe}_{\mathrm{x}} \mathrm{O}_{3}$ at RT (Imma space group). $\mathrm{V}$ is the cell volume; $\mathrm{B}_{\text {iso }}$ is the overall isotropic thermal parameter; TM-O the bond lengths between $\mathrm{TM}=(\mathrm{Mn}, \mathrm{Fe})$ and $\mathrm{O}$ and TM-O-TM are the bond angles, $\mathrm{G}_{\mathrm{s}}$ is the average grain size. $\mathrm{R}_{\mathrm{wp}}, \mathrm{R}_{\mathrm{p}}$ and $\mathrm{R}_{\mathrm{F}}$ are the agreement factors for the weighted profiles, the profiles and the structure factors; $\chi^{2}$ is the goodness of fit. The numbers in parentheses are estimated standard deviations to the last significant digit.

\begin{tabular}{|c|c|c|c|c|c|c|}
\hline & \multicolumn{6}{|c|}{$\mathbf{x}$} \\
\hline & $\mathbf{0}$ & $\mathbf{0}$ & 0.05 & 0.1 & 0.15 & 0.15 \\
\hline Diffraction & XRD & PND & XRD & XRD & XRD & PND \\
\hline \multicolumn{7}{|l|}{ Cell parameters } \\
\hline $\mathrm{a}(\mathrm{nm})$ & $0.550037(2)$ & $0.55028(4)$ & $0.550062(3)$ & $0.549935(3)$ & $0.550084(3)$ & $0.55213(3)$ \\
\hline$b(n m)$ & $0.776402(4)$ & $0.78089(4)$ & $0.776633(4)$ & $0.776676(4)$ & $0.776855(3)$ & $0.77809(4)$ \\
\hline $\mathrm{c}(\mathrm{nm})$ & $0.551929(4)$ & $0.55084(4)$ & $0.552185(2)$ & $0.552247(2)$ & $0.552184(2)$ & $0.55108(3)$ \\
\hline $\mathrm{V}\left(\mathrm{nm}^{3}\right)$ & $0.23570(2)$ & $0.2367(2)$ & $0.23589(1)$ & $0.23588(1)$ & $0.23597(1)$ & $0.2368(1)$ \\
\hline \multicolumn{7}{|l|}{ Atoms } \\
\hline $\mathrm{Pr} / \mathrm{Ba}$ & $0.003(1)$ & $0.034(2)$ & $0.004(1)$ & $0.0010(1)$ & $0.003(1)$ & $0.035(2)$ \\
\hline $\mathrm{B}_{\text {iso }}\left(\mathrm{nm}^{2}\right)$ & $0.0046(3)$ & 0.001947 & $0.0063(3)$ & $0.0059(3)$ & $0.0066(3)$ & $0.006(4)$ \\
\hline $\mathrm{Mn} / \mathrm{Fe} \mathrm{B}_{\text {iso }}\left(\mathrm{nm}^{2}\right)$ & $0.0011(3)$ & 0.0028833 & $0.0060(5)$ & $0.0042(5)$ & $0.0078(4)$ & 0.0024403 \\
\hline $\mathrm{O}(1)$ & 0.56 & 0.56 & 0.56 & 0.56 & $0.562(2)$ & 0.56 \\
\hline $\mathrm{B}_{\text {iso }}\left(\mathrm{nm}^{2}\right)$ & 0.01 & 0.01 & 0.01 & 0.01 & 0.01 & 0.01 \\
\hline $\mathrm{O}(2)$ & -0.00061 & -0.0006 & -0.0006 & -0.00073 & -0.00088 & -0.00088 \\
\hline $\mathrm{B}_{\text {iso }}\left(\mathrm{nm}^{2}\right)$ & 0.02 & 0.02 & 0.02 & 0.02 & 0.02 & 0.02 \\
\hline \multicolumn{7}{|l|}{ Structural parameters } \\
\hline TM-O(1) (nm) & 0.1969052 & 0.198 & 0.1969647 & 0.1969759 & 0.19721 & 0.197313 \\
\hline TM-O(2) (nm) & 0.1948028 & 0.194653 & 0.1948527 & 0.1948413 & 0.1948568 & 0.195023 \\
\hline TM-O(1)-TM $\left(^{\circ}\right)$ & 160.6358 & 160.782 & 160.6327 & 160.6316 & 160.01 & 160.706 \\
\hline TM-O(2)-TM $\left(^{\circ}\right)$ & 179.7223 & 179.725 & 179.6816 & 179.6672 & 179.5970 & 179.635 \\
\hline $\mathrm{G}_{\mathrm{s}}(\mathrm{nm})$ & 48.5 & - & 54.86 & 52.46 & 60.61 & - \\
\hline \multicolumn{7}{|l|}{ Agreement factors } \\
\hline $\mathrm{R}_{\mathrm{wp}}(\%)$ & 2.00 & 4.15 & 1.98 & 2 & 1.80 & 3.74 \\
\hline $\mathrm{R}_{\mathrm{p}}(\%)$ & 1.48 & 2.79 & 1.44 & 1.47 & 1.37 & 2.51 \\
\hline $\mathrm{R}_{\mathrm{F}}(\%)$ & 4.90 & 2.12 & 3.97 & 4.60 & 3.13 & 2.01 \\
\hline$\chi^{2}$ & 1.51 & & 1.53 & 1.55 & 1.23 & \\
\hline
\end{tabular}

The average crystallites sizes obtained from the XRD refinement are reported in table 1 and range from $48-61 \mathrm{~nm}$. These values are much lower than the micrometer size of grains observed by SEM indicating an intrinsic disorder within the grains. This point could affect to some extent the magnetic and electrical properties.

\subsection{Magnetic Properties}

$M(T)$ curves measured at constant magnetic field of 500 Oe and $M(H)$ measurements at $10 \mathrm{~K}$ are shown in Fig. 2. 

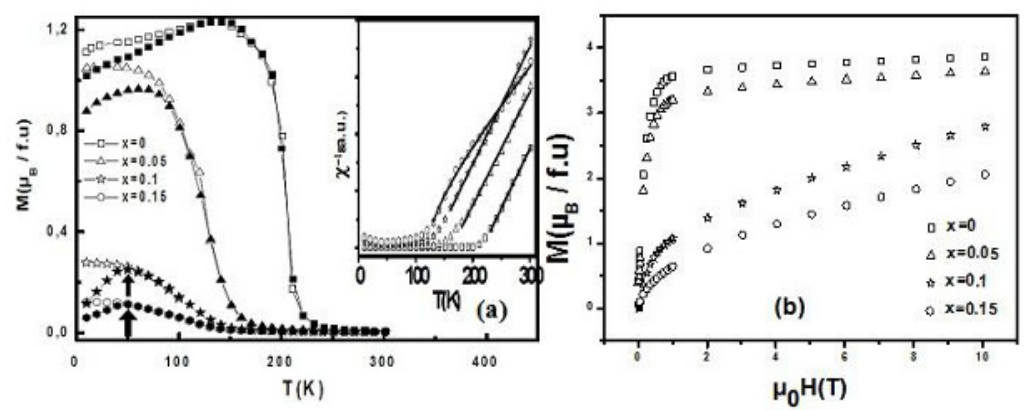

Fig. 2. Magnetic measurements for $\mathrm{Pr}_{0.67} \mathrm{Ba}_{0.33} \mathrm{Mn}_{1-\mathrm{x}} \mathrm{Fe}_{\mathrm{x}} \mathrm{O}_{3}$. (a) $M(T)$ curves at $\mu_{0} \mathrm{H}=500$ Oe magnetic field in FC (open symbols) and ZFC (close symbols). The arrows indicate $T m$ for $\mathrm{x}=0.1$ and $0.15 \mathrm{Fe}$ amount. The inset shows the inverse of magnetic susceptibility $(1 / \chi)$ vs. T plots and the black solid line in these plots represents the fit of the high-T region (see text). (b) $M(H)$ curves at $10 \mathrm{~K}$.

These results show for $\mathrm{x}=0$ and $\mathrm{x}=0.05$ samples a clear PM to FM phase transition resulting in an increase of $M$ at low T in Fig.2 (a). The corresponding $M(H)$ curves at $10 \mathrm{~K}$ (Fig. 2 (b)) show a typical FM regime with a sharp increase of $M$ at low field corresponding to rearrangement of ferromagnetic domains. $M$ reaches rapidly an almost constant value for higher fields corresponding to parallel alignment of the spins. In the following $M$ measured in $100 \mathrm{kOe}$ at $10 \mathrm{~K}$ will be identified with the saturation magnetization $\mathrm{M}_{\mathrm{s}}^{\text {meas }}$. The measured saturation moment expressed in Bohr magneton per atomic formula unit $\mu_{\mathrm{s}}^{\text {meas }}=\mathrm{M}_{\mathrm{s}}^{\text {meas }} \mathrm{M}_{\mathrm{m}} / \mathrm{N}_{\mathrm{a}} \mu_{\mathrm{B}}$ (with $\mathrm{N}_{\mathrm{a}}$ the Avogadro number, $\mathrm{M}_{\mathrm{m}}$ the molecular mass per unit formula and $\mu_{\mathrm{B}}$ the Bohr magneton) is given in table 2. For samples with $\mathrm{x}$ $\mu 0.05, \mu_{\mathrm{s}}{ }^{\text {meas }}$ can be compared with the moment $\mu_{\mathrm{s}}^{\text {cal }}$ calculated for a full spin alignment in the limit $\mathrm{T}=0 \mathrm{~K}$. The $\mu_{\mathrm{s}}^{\text {cal }}$ values given in table 2 have been obtained assuming only Mn and Fe ferromagnetic contribution with a quenched orbital moment, $\mathrm{S}=2$ for $\mathrm{Mn}^{3+}, \mathrm{S}=3 / 2$ for $\mathrm{Mn}^{4+}, \mathrm{S}=5 / 2$ for $\mathrm{Fe}^{3+}$ and g $=2$ for both $\mathrm{Mn}^{3+}, \mathrm{Mn}^{4+}$ and $\mathrm{Fe}^{3+}$. The $\mathrm{Mn}^{3+}$ and $\mathrm{Mn}^{4+}$ concentrations (also given in table 2) are deduced from the composition of the manganite phase under the assumption of substitution of $\mathrm{Mn}^{3+}$ by $\mathrm{Fe}^{3+}$. The observed and calculated moments coincide reasonably, which confirms that, despite $\mathrm{Fe}$ substitution, a FM state is present in samples with $\mathrm{x} \leq 0.05$. Note that this comparison can only be taken as qualitative since a more complicated magnetic state should be probably taken into account. Furthermore the unavoidable uncertainties on the $\mathrm{O}$ content lead to large variations in the $\mathrm{Mn}^{3+}$ and $\mathrm{Mn}^{4+}$ concentrations and strongly affect the calculated moment. Finally we noted that the ferromagnetic regime observed for $\mathrm{x}=0$ sample shows a slightly unsaturated magnetization corresponding to realignment of the spins induced by the external field that could be due either to canted long range ordering of the $\mathrm{Mn} / \mathrm{Pr}$ spins and/or to a magnetic disorder state of $\operatorname{Pr}$ (in this scenario the external field induces an additional polarization of Pr superimposed to the one due to the internal field due to Mn spins).

A reasonable estimation of the Curie temperature $T_{C}$ can be obtained by determining the temperature of the maximum of $\mathrm{d} M(T) / \mathrm{d} T$ (table 2). Our $T_{C}$ value for undoped compound, $205 \mathrm{~K}$, is close to that reported in the literature ranging from $167 \mathrm{~K}$ to $195 \mathrm{~K}\left(T_{C}=180 \mathrm{~K}[13]\right.$ and $T_{C}=167 \mathrm{~K}$ [15]) and a decrease of $T_{C}$ is observed for $\mathrm{x}=0.05$ doped sample. Substitution of $\mathrm{Fe}$ at the $\mathrm{Mn}$ site weakens the FM interactions and reduces both $T_{C}$ and $\mu_{\mathrm{s}}^{\text {meas }}$ (see table 2).

Table 2. Magnetic transition temperature $T_{C}$ or $T_{m}$ (see text) for $\mathrm{Pr}_{0.67} \mathrm{Ba}_{0.33} \mathrm{Mn}_{1-\mathrm{x}} \mathrm{Fe}_{\mathrm{x}} \mathrm{O}_{3}$ samples. Experimental and calculated magnetic saturation moments $\mu_{S}{ }^{\text {meas }}$ and $\mu_{S}{ }^{\text {cal }}$. Curie Weiss temperature $\Theta$, experimental $\left(\mu_{\text {eff }}^{\text {meas }}\right)$ and calculated $\left(\mu_{\text {eff }}^{\text {th }}\right)$ effective paramagnetic moments.

\begin{tabular}{llccccc}
\hline $\mathrm{x}$ & $\mathrm{T}_{\mathrm{C}}$ or $\mathrm{T}_{\mathrm{m}}(\mathrm{K})$ & $\mu_{\mathrm{S}}{ }^{\text {cal }}\left(\mu_{\mathrm{B}} /\right.$ f.u. $)$ & $\mu_{\mathrm{S}}^{\text {meas }}\left(\mu_{\mathrm{B}} /\right.$ f.u. $)$ & $\Theta(\mathrm{K})$ & $\mu_{\text {eff }}^{\text {meas }}\left(\mu_{\mathrm{B}}\right)$ & $\mu_{\text {eff }}^{\text {th }}\left(\mu_{\mathrm{B}}\right)$ \\
\hline 0 & 205 & 3.67 & 3.86 & 215 & 7.25 & 5.44 \\
0.05 & 128 & 3.72 & 3.63 & 155 & 7.77 & 5.49 \\
0.1 & 50 & 3.77 & 2.79 & 134 & 5.69 & 5.44 \\
0.15 & 50 & 3.82 & 2.05 & $112,-16$ & 7.10 & 5.59 \\
\hline
\end{tabular}


For $\mathrm{x}=0.1$ and 0.15 samples the $M(T)$ curves in Fig.2 (a) have no sharp increase and a low $M$ magnitude. The temperature $\left(T_{m}=50 \mathrm{~K}\right)$ reported in table 2 corresponds to the maximum value of the ZFC curve. At $T_{m}$, a bifurcation between the FC and ZFC curves ( $\lambda$ shape) is observed which is generally associated in the literature of manganites with a magnetic glass state (cluster or spin - glass [16]). $M(H)$ measurements at $10 \mathrm{~K}$ (see Fig. 2 (b)) show that $M$ for $\mathrm{x}=0.1$ and 0.15 do not exhibit a FM regime as there is neither a sharp increase and nor a saturation value of $M$ with the applied field that could correspond to parallel spin alignment.

The inverse of the susceptibility (calculated from data of Fig. 2 (a)) is shown in the inset, as a function of temperature in the PM region (above $T_{C}$ or $T_{m}$ ). It can be generally fitted by a Curie Weiss law: $\chi=\frac{C}{\mathrm{~T}-\Theta}$ with $\Theta$ the Curie Weiss temperature and $C$ the Curie constant defined as $C=\frac{1}{3 k_{B}} \frac{N_{a}}{M_{m}} \mu_{e f f}^{\text {meas }^{2}} \mu_{B}^{2}, \mathrm{k}_{\mathrm{B}}$ the Boltzmann constant, and $\mu_{\mathrm{eff}}^{\text {meas }}$ the effective moment expressed in Bohr magnetons. The obtained $\Theta$ values (see table 2 ) are generally positive and decrease with $\mathrm{Fe}$ content following the same trend as $T_{C}$ or $T_{m}$. The positive value of $\Theta$ confirms a mean FM interaction between spins for all samples. One can compare the measured effective moment with the calculated one $\mu_{\text {eff }}{ }^{\text {th }}=\sqrt{\sum_{i} c_{i} \mu_{i}{ }^{2}}$, using cation concentrations $\left(c_{i}\right)$ and individual cation theoretical effective paramagnetic moment $\left(\mu_{\mathrm{i}}\right)$. One finds that for $\mathrm{FM} \mathrm{x}=0$ and $\mathrm{x}=0.05$ samples the measured effective magnetic moments in the PM regime are significantly larger than the calculated ones. This result is commonly observed in manganites (see by example Blanco et al. [17, 18] and is generally attributed to the existence of short range $\mathrm{FM}$ interactions above $\mathrm{T}_{\mathrm{C}}$. For the non $\mathrm{FM} \mathrm{x}=0.1$ and $\mathrm{x}=$ 0.15 samples a different behaviour is observed. For sample with $\mathrm{x}=0.1$ (inset of Fig. 2 (a)) we observed a linear behaviour well above $T_{m}$ with a value of $\mu_{\text {eff }}^{\text {meas }}$ almost equal to the theoretical value $\mu_{\mathrm{eff}}^{\text {th }}$ appearing as a normal PM region whereas a complex behaviour is observed for sample with $\mathrm{x}=0.15$ above $\mathrm{T}_{\mathrm{m}}$. This type of curve is commonly observed in manganites and is generally explained as arising from inhomogeneous systems (phase segregation) that are believed to be the key for understanding CMR properties [4, 5]. A deviation from the linear paramagnetic region [180 K$300 \mathrm{~K}$ ] is observed below $180 \mathrm{~K}$ and the data can be fitted in this region [130 K-300 K] by considering a two phases models (FM, AFM contributions) with two distinct transition temperatures, $\Theta_{\mathrm{F}}$ and $\Theta_{\mathrm{N}}$ following $\chi=\beta \frac{C}{T-\Theta_{F}}+(1-\beta) \frac{2 C}{T-\Theta_{N}}$ where $\beta$ (fixed to 0.5 ) corresponds to the proportion of the AFM phase with negative Néel transition temperature $\Theta_{\mathrm{N}}$. Results of this fit are indicated by solid lines in the inset of Fig. 2 and in Table $2\left(\Theta_{N}\right.$ is indicated by the negative value). The negative value of $\Theta_{\mathrm{N}}$ and the reduction (inset of Fig. 2 (a)) of the slope, corresponding to the coefficient $2 \mathrm{C}$, are strong indications of AFM contribution in this sample and a phase separation [4, 5] tendency of the system beyond $10 \%$ of Fe amount is expected.

Further experiments are necessary to fully understand how Fe doping affects the magnetic state of these samples but strong indication of AFM and FM competing interaction is expected from our observations for $\mathrm{x}=0.15$ sample. Indeed local AFM superexchange interactions between Fe and Mn ions are expected in our system as no competing DE (FM) interactions are possible [19-21]. This point is confirmed by our $\mathrm{M}_{\mathrm{s}}^{\text {meas }}$ value for $\mathrm{x}=0.05$ lower than the one for $\mathrm{x}=0$ whereas a larger value would be expected for a FM full spin alignment $\left(\mathrm{Fe}^{3+}\right.$ contributes with $5 \mu \mathrm{B}$ whereas $\mathrm{Mn}^{3+}$ contributes with $4 \mu \mathrm{B}$ ). Blanco et al. reported spin glass behavior arising from competing $\mathrm{FM}$ and AFM interactions in $\mathrm{Nd}_{0.7} \mathrm{~Pb}_{0.3} \mathrm{Mn}_{1-\mathrm{x}} \mathrm{Fe}_{\mathrm{x}} \mathrm{O}_{3}[17,18]$ system. In particular sample with Fe content $\mathrm{x}=$ 0.075 in their Fig. 3 shows a behavior reminiscent of FM to AFM phase transition (typically observed in $\operatorname{Pr}_{0.5} \mathrm{Sr}_{0.5} \mathrm{MnO}_{3}$ [22]) and their $\mathrm{Nd}_{0.7} \mathrm{~Pb}_{0.3} \mathrm{Mn}_{0.9} \mathrm{Fe}_{0.1} \mathrm{O}_{3}$ sample presents very similar $\lambda$ shape as our non FM samples. A complex magnetic state due to a mixture of AFM and FM sate is observed for $\operatorname{Pr}_{0.67} \mathrm{Ca}_{0.33} \mathrm{MnO}_{3}$ sample [23]. 


\subsection{Transport properties}

Fig. 3 shows the transport properties for selected samples $(\mathrm{x}=0, \mathrm{x}=0.05$ and $\mathrm{x}=0.15)$. The samples with $\mathrm{x}=0$ and $\mathrm{x}=0.05$ exhibit a metallic behaviour at low temperature. For these samples a phase transition from metallic to a high temperature semiconducting state is characterized by a maximum resistance at temperature $T_{P}$ indicated by arrows in Fig. 3. For $x=0$ sample this value of $T_{P}$ is lower than $T_{C}\left(68 \mathrm{~K}\right.$ temperature difference between $T_{C}(205 \mathrm{~K})$ and $\mathrm{T}_{\mathrm{P}}(137 \mathrm{~K})$ for $\left.\mathrm{x}=0\right)$ and for comparison no clear transition was observed in $M(T)$ curve in ref. [13] where $\mathrm{T}_{\mathrm{P}}=120 \mathrm{~K}$ for $\mathrm{x}=$ 0 ). For our samples $T_{P}$ decreases with the increase of $F e$ content $\left(T_{P}=137 \mathrm{~K}\right.$ for $x=0$ and $T_{P}=75 \mathrm{~K}$ for $\mathrm{x}=0.05$ ) which can be directly related to a decrease of the ratio of $\mathrm{Mn}^{3+} / \mathrm{Mn}^{4+}$ that weakens the $\mathrm{Mn}^{3+}-\mathrm{O}-\mathrm{Mn}^{4+}$ DE FMM interactions $[19,24]\left(\mathrm{Fe}^{3+}-\mathrm{O}-\mathrm{Fe}^{3+}\right.$ and $\mathrm{Mn}^{3+}-\mathrm{O}-\mathrm{Fe}^{3+}$ do not allow active $\mathrm{DE})$.

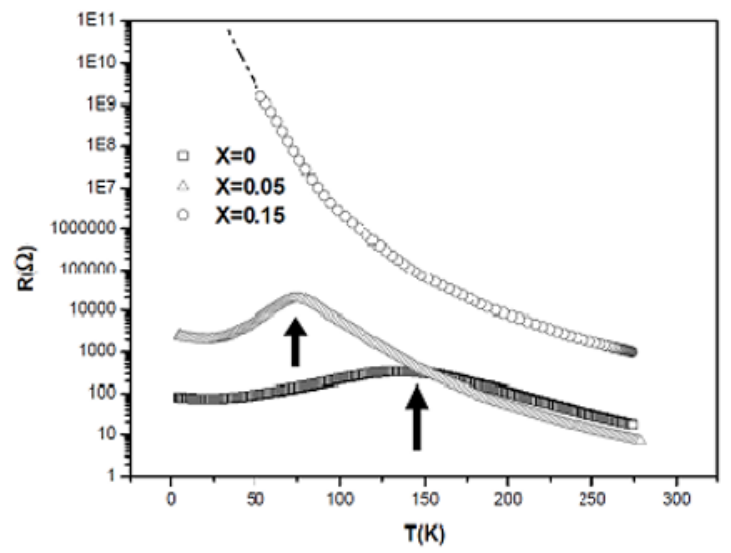

Fig. 3. Zero field resistance vs. temperature curves for $\mathrm{Pr}_{0.67} \mathrm{Ba}_{0.33} \mathrm{Mn}_{1-\mathrm{x}} \mathrm{Fe}_{\mathrm{x}} \mathrm{O}_{3}(\mathrm{x}=0, \mathrm{x}=0.05$ and $\mathrm{x}=0.15)$ samples. The arrows indicate the metal-insulator phase transition

For the $\mathrm{x}=0.15$ sample the decrease of the ratio of $\mathrm{Mn}^{3+} / \mathrm{Mn}^{4+}$ appears to be too important to retain a metallic state: a semiconducting behavior is observed in all the temperature range. Consequently, the doping of Fe in these manganites $\operatorname{Pr}_{0.67} \mathrm{Ba}_{0.33} \mathrm{Mn}_{1-\mathrm{x}} \mathrm{Fe}_{\mathrm{x}} \mathrm{O}_{3}(\mathrm{x}=0-0.15)$ results in a reduction in the number of available hopping electron, which removes the metallicity and establishes semiconducting behavior.

\section{Conclusions}

We have studied the effect of Fe doping at Mn- site on electrical and magnetic properties of $\mathrm{Pr}_{0.67} \mathrm{Ba}_{0.33} \mathrm{Mn}_{1-\mathrm{x}} \mathrm{Fe}_{\mathrm{x}} \mathrm{O}_{3}(0 \leq \mathrm{x} \leq 0.15)$ manganese oxide. Powder XRD and PND structure analysis and morphological investigation have shown that structural parameters and grain sizes are almost not affected by Fe doping. Magnetic and electrical measurements show a FMM - PMI transition with a reduction in both $\mathrm{T}_{\mathrm{C}}$ and $\mathrm{T}_{\mathrm{P}}$ and a decrease (respectively an increase) of the magnetization (respectively of the resistivity) with increasing Fe content. No FMM-PMI transition was observed above $10 \% \mathrm{Fe}$ amount. In the PM region, the two FM samples ( $\mathrm{x}=0$ and 0.05$)$ present short range $\mathrm{FM}$ interactions above $\mathrm{T}_{\mathrm{C}}$. The $\mathrm{x}=0.1$ sample presents a normal $\mathrm{PM}$ behavior, whereas for $\mathrm{x}=0.15$ sample the data were well fitted by considering two Curie laws corresponding to FM and AFM behaviors with two distinct transition temperatures, $\Theta_{\mathrm{F}}$ and $\Theta_{\mathrm{N}}$. ZFC $M(T)$ measurements is compatible with a magnetic glass state below $50 \mathrm{~K}$ for $\mathrm{x}=0.1$ and 0.15 compounds. $M(H)$ measurements at $10 \mathrm{~K}$ show that the materials with 0 and $5 \% \mathrm{Fe}^{3+}$ content, exhibit FM behavior while beyond that concentration there is probably a competition of both FM and AFM behaviours. Changes in these properties have been analyzed on the basis that the substitution of $\mathrm{Fe}^{3+}$ for $\mathrm{Mn}^{3+}$ reduces the double exchange (DE) FMM interaction. 


\section{EMM-FM2011}

\section{Acknowledgments}

Institut Laue Langevin is kindly acknowledged for help and allocation of beam time for neutron diffraction experiment. M. Baazaoui gratefully thanks the region Rhône-Alpes for allocation of a TEMPRA Grant.

\section{References}

1. R. Von Helmolt, J. Wecker, B. Holzapfel, L. Schultz, K. Samwer, Phys. Rev. Lett.71 (1993) 2331-2333.

2. C. Zener, Phys. Rev. 82 (1951) 403-405. P.W. Anderson, H. Hasegawa, Phys. Rev. 100 (1955) 675-681.P.G. Degennes, Phys. Rev. 118 (1960) 141.

3. A.J. Millis, P.B. Littlewood, B.I. Chairman, Phys. Rev. Lett. 74, (1995) 5144-5147.

4. E. Dagotto, T. Hotta, A. Moreo, Phys. Rep. 344 (2001) 1-153.

5. M. Tovar, M.T. Causa, C.A. Ramos, D. Laura-Ccahuana, J. Magn. Magn. Mater. 320 (2008) 523-527.

6. M. P. Brown and K. Austin, The New Physique, Publisher City: Publisher Name, 2005, pp. 2530.

7. A. Gasmi, M. Boudard, S. Zemni, F. Hippert and M. Oumezzine, J. Phys. D: Appl. Phys. 42 (2009) 225408 (7pp).

8. M. Baazaoui, S. Zemni, M. Boudard, H. Rahmouni, A. Gasmi, A. Selmi, M. Oumezzine Mater. Lett. 63 (2009) 2167-2170.

9. M. Baazaoui, S. Zemni, M. Boudard, H. Rahmouni, M. Oumezzine A. Selmi, Physica B 405 (2010) 1470-1474.

10. M. Baazaoui, M. Boudard, S. Zemni, Mater. Lett. 65 (2011) 2093-2095.

11. R. A. Young, the Rietveld Method, Oxford University Press, New York, 1993. J. RodriguezCarvajal, FULLPROF, LLB Saclay, France, 2001.

12. F. Damay, Z. Jirak, M. Hervieu, C. Martin, A. Maignan, B. Raveau,G. André, F. Bourée, J. Magn. Magn. Mat. 190 (1998) 221-232.

13. A. K. Heilman, Y.Y. Xue, B. Lorenz, B.J. Campbell, J. Cmaidalka, R.L. Meng, Y.S. Wang, C.W. Chu, Phys. Rev. B 65 (2002) 214423-214425.

14. R. D. Shannon, Acta Crystallogr. A 32 (1976) 751-764.

15. D. C. Krishna, P. Venugopal Reddy, J. Alloy. Compd. 479 (2009) 661-669.

16. J. A. Mydosh, in Spin Glass: An experimental Introduction, Taylor \& Francis ed., London, 1993.

17. J. J. Blanco, M. Insausti, I. Gil de Muro, L. Lezama, T. Rojo, J. Sol. Stat. Chem. 179 (2006) 623-631.

18. J.J. Blanco, L. Lezama, M. Insausti, J. Gutierrez, J.M. Barandiaran, T. Rojo, Chem. Mater. 11 (1999) 3464-3469.

19. A. G. Mostafa, E.K. Abdel-Khalek, W.M. Daoush, S.F. Moustafa, J. Magn. Magn. Mater. 320 (2008) 3356-3360.

20. K.H. Ahn, X.W. Wu, K. Liu, C.L. Chien, Phys. Rev. B 54(1996) 15299-15302. J. Appl. Phys. 81 (1997) 5505.

21. J. Gutierrez, A. Pena, J. M. Barandiaran, J. L. Pizarro, T. Hemandez, L. Lezama, M. Insausti, T. Rojo, Phys. Rev. B 61 (2000) 9028-9035.

22. W. Boujelben, A. Cheikh-Rouhou, J. Pierre, J. C. Joubert, J. Alloy. Compd. 314 (2001) 15-21.

23. F. Rivadulla, M.A. López-Quintela, L.E. Hueso, C. Jardón, A. Fondado, J. Rivas, M.T. Causac, R.D. Sánchez, Solid State Commun., 110 (1999) 179-183.

24. S. Bhattacharya, S. Pal, R.K. Mukherjee, B.K. Chaudhuri, S. Neeleshwar, Y.Y. Chen, S. Mollah, H.D. Yang, J. Magn. Magn. Mater. 269 (2004) 359-371 